Article

\title{
Functional Blockade of E-Selectin in Tumor-Associated Vessels Enhances Anti-Tumor Effect of Doxorubicin in Breast Cancer
}

\author{
Yoshihiro Morita ${ }^{1}$, Macall Leslie ${ }^{1}$, Hiroyasu Kameyama ${ }^{1}$, Ganesh L. R. Lokesh ${ }^{2}$, \\ Norihisa Ichimura ${ }^{1}$, Rachel Davis ${ }^{3}$, Natalie Hills ${ }^{3}$, Nafis Hasan ${ }^{4}$, Roy Zhang ${ }^{5}$, Yuji Kondo ${ }^{6}$, \\ David G. Gorenstein ${ }^{7}$, David E. Volk ${ }^{2}$ D, Inna Chervoneva ${ }^{8}$, Hallgeir Rui ${ }^{9}$ and \\ Takemi Tanaka $1,5, *$ \\ 1 Stephenson Cancer Center, University of Oklahoma Health Sciences Center, 975 NE, 10th, \\ Oklahoma City, OK 73104, USA; yoshi197@dent.osaka-u.ac.jp (Y.M.); macall-leslie@ouhsc.edu (M.L.); \\ hiroyasu-kameyama@ouhsc.edu (H.K.); norihisa@med.nagoya-u.ac.jp (N.I.) \\ 2 McGovern Medical School, Institute of Molecular Medicine, University of Texas Health Science Center at \\ Houston, 1825 Hermann Pressler, Houston, TX 77030, USA; ganesh@uth.tmc.edu (G.L.R.L.); \\ David.Volk@uth.tmc.edu (D.E.V.) \\ 3 School of Medicine, University of Oklahoma Health Sciences Center, 800 Stanton L. Young Blvd., \\ Oklahoma City, OK 73104, USA; rachel-davis@ouhsc.edu (R.D.); Natalie-Hills@ouhsc.edu (N.H.) \\ 4 Department of Pharmaceutical Sciences, Thomas Jefferson University, 1020 Locust St, \\ Philadelphia, PA 19107, USA; nafis.hasan@tufts.edu \\ 5 Department of Pathology, College of Medicine, University of Oklahoma Health Sciences Center, 940 SL \\ Young Blvd, Oklahoma City, OK 73104, USA; roy-zhang@ouhsc.edu \\ 6 Cardiovascular Biology Research Program, Oklahoma Medical Research Foundation, 825 NE. 13th, \\ Oklahoma City, OK 73104, USA; Yuji-Kondo@omrf.org \\ 7 AM Biotechnologies, LLC, 12521 Gulf Freeway, Houston, TX 77034, USA; david.nmr@earthlink.net \\ 8 Department of Pharmacology and Experimental Therapeutics, Thomas Jefferson University, 1015 Chestnut \\ St., Philadelphia, PA 19107, USA; Inna.Chervoneva@jefferson.edu \\ 9 Department of Pathology, Medical College of Wisconsin, 8701 Watertown Plank Rd, \\ Milwaukee, WI 53226, USA; hrui@mcw.edu \\ * Correspondence: takemi-tanaka@ouhsc.edu; Tel.: +1-(405)-271-8260
}

Received: 30 January 2020; Accepted: 11 March 2020; Published: 19 March 2020

check for updates

\begin{abstract}
Chemotherapy is a mainstay of treatment for solid tumors. However, little is known about how therapy-induced immune cell infiltration may affect therapy response. We found substantial $\mathrm{CD}_{4} 5^{+}$immune cell density adjacent to E-selectin expressing inflamed vessels in doxorubicin (DOX)-treated residual human breast tumors. While CD45 level was significantly elevated in DOX-treated wildtype mice, it remained unchanged in DOX-treated tumors from E-selectin null mice. Similarly, intravenous administration of anti-E-selectin aptamer (ESTA) resulted in a significant reduction in $\mathrm{CD} 45^{+}$immune cell density in DOX-treated residual tumors, which coincided with a delay in tumor growth and lung metastasis in MMTV-pyMT mice. Additionally, both tumor infiltrating T-lymphocytes and tumor associated-macrophages were skewed towards $\mathrm{T}_{\mathrm{H}} 2$ in DOX-treated residual breast tumors; however, ESTA suppressed these changes. This study suggests that DOX treatment instigates de novo intratumoral infiltration of immune cells through E-selectin, and functional blockade of E-selectin may reduce residual tumor burden as well as metastasis through suppression of $\mathrm{T}_{\mathrm{H}} 2$ shift.
\end{abstract}

Keywords: E-selectin; aptamer; doxorubicin; tumor-associated-macrophages 


\section{Introduction}

Neoadjuvant chemotherapy is indicated for invasive breast cancer treatment as a strategy to improve local control by reducing large, inoperable tumors to a size amenable to surgical resection [1] and to gain systemic control over micrometastases [2,3]. While over $80 \%$ of breast tumors clinically respond to combination chemotherapy with a measurable size reduction [3], the likelihood of complete tumor eradication (complete pathologic response) is relatively low and residual tumor remains in $70-85 \%$ of cases $[4,5]$. Studies suggest a possible predictive role of pre-treated tumor stroma composition in response to neoadjuvant chemotherapy. In chemotherapy-naïve breast tumors the prevalence of tumor associated macrophages (TAMs) as well as T-lymphocytes (TIL) is inversely associated with chemotherapy response [6,7]. Similarly, studies reported a predictive role of de novo infiltration of immune cells into tumors on the outcome. Clinical studies showed that increased immune cell infiltration during chemotherapy is correlated with higher residual tumor burden and adverse clinical outcomes [8,9]. Preclinical studies also indicated an increase in immune cell density in chemotherapy-treated residual breast tumors, and pharmacologic inhibition of immune cell infiltration improved therapeutic efficacy [6-11]. These studies suggest possible negative impacts of therapy-related de novo immune cell infiltration on therapeutic efficacy.

Doxorubicin (DOX) is indicated for treatment of invasive breast cancer as a part of combination chemotherapy. DOX causes cytotoxic death of cycling cells [6], which instigate successive infiltration of immune cells [12]. Infiltration of immune cells into damaged tissue from the circulation is governed by the adhesion cascade, where circulating cells adhere to and transmigrate through inflamed vessels under swift blood flow [13-15]. E-selectin (CD62E, ELAM-1, LECAM-2) expression on vascular surfaces is a hallmark of inflammation that mediates capture of circulating immune cells on the vessel surface through affinity binding with its counter ligands (sLex, sLeA, CD44 (HCELL), and PSGL) [16]. E-selectin expression is spatiotemporally limited and induced in response to inflammatory cytokines [17]. Accordingly, E-selectin expression in tumor-associated vessels is elevated in different types of carcinomas [18-20], and the abundance of sLex positive immune infiltrates in the tumor is inversely associated with prognosis [17]. Therefore, we hypothesized that functional blockade of E-selectin reduces chemotherapy-associated de novo infiltration of immune cells by obstructing their entry to the tumor, in turn, mitigating residual tumor burden.

\section{Results}

\subsection{High $C D 45^{+}$Immune Cell Density in Chemotherapy-Treated Residual Breast Tumors}

To assess the association between immune cell density and therapy response, we histopathologically quantified $\mathrm{CD} 45^{+}$immune cells and E-selectin ${ }^{+}$inflamed vessel density in surgically resected invasive human breast tumors (Stage II-III), treated with DOX-containing neoadjuvant chemotherapy (Supplementary Figures S1 and S2). CD $45^{+}$cells were densely present in $57 \%$ cases with residual tumor, yet only noted in $6 \%$ cases with no residual tumor (Figure 1a). Vessels adjacent to the residual tumor were inflamed as characterized by elevated expression of E-selectin (Figure 1a). Inflammation score, defined by the abundance of $\mathrm{CD} 45^{+}$immune cell clusters and E-selectin ${ }^{+}$vessels, was disproportionally high around residual human breast tumors (score of 3 in $42 \%$ of residual vs. $6 \%$ of no residual tumor cases; Figure 1a). The spatial proximity of $\mathrm{CD} 45^{+}$immune cell clusters and E-selectin ${ }^{+}$vessels suggested a possible role of E-selectin as the gateway for circulating immune cells. E-selectin null (E-selectin ${ }^{-/}$) or wildtype (WT) mice bearing 4T1 murine breast tumors were treated once weekly with intravenous injection of saline or low dose DOX $(0.5 \mathrm{mg} / \mathrm{kg})$. DOX treatment resulted in a 4.6-fold increase of $\mathrm{CD} 45^{+}$immune cell density compared to the saline control group in WT mice (Figure $1 \mathrm{~b}$ ), whereas the $\mathrm{CD} 45^{+}$density remained unchanged (1.1 fold over saline control) in E-selectin ${ }^{-/-}$mice. Although once a week treatment with low dose DOX showed no significant effect on tumor growth in WT mice (7.1\% growth reduction; Figure 1c), the tumor growth rate of DOX-treated $\mathrm{E}-s e l e c t i n^{-/-}$mice was markedly augmented (39.8\%) compared to saline controls (Figure 1c). No 
significant weight loss was noted among any treatment group (Supplementary Figure S3). Together, this data suggests a new therapeutic opportunity by blocking DOX treatment-related immune cell infiltration via E-selectin for the improvement of anti-tumor therapy.

(a)

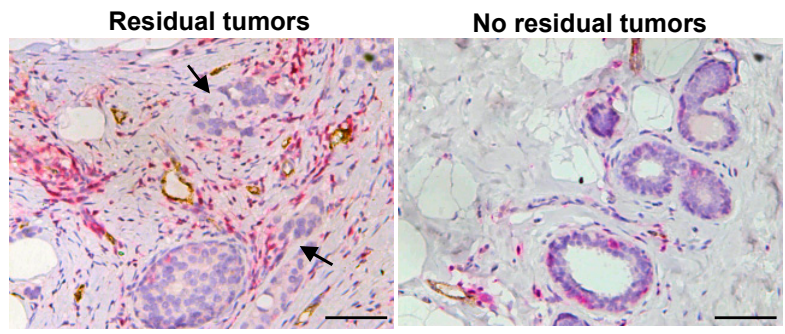

(b)
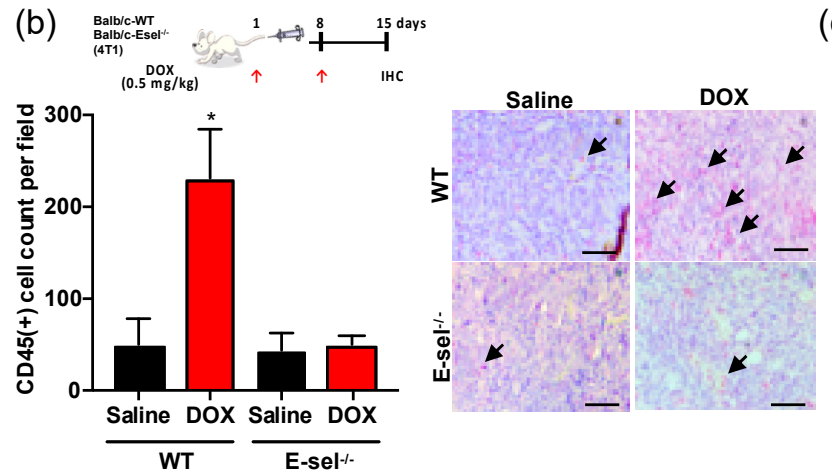
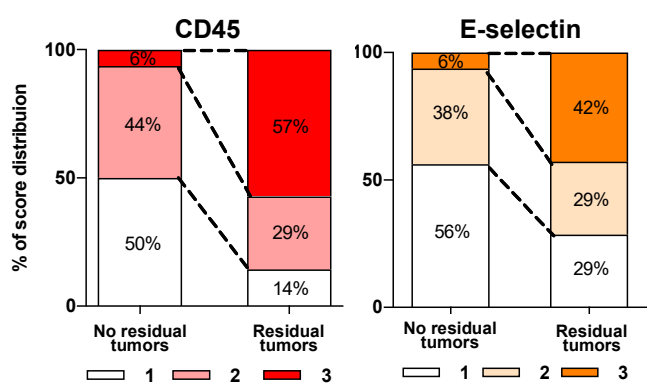

(c)

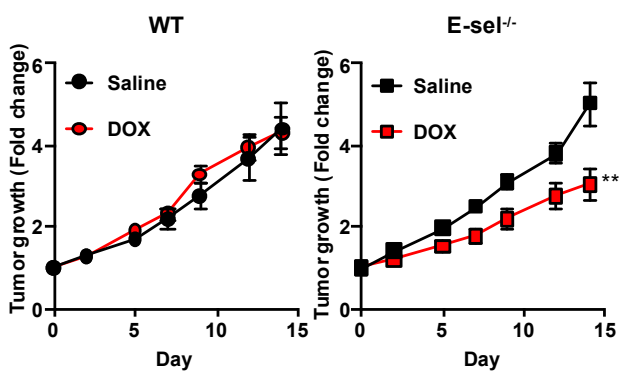

Figure 1. High CD45 $5^{+}$density in DOX-treated breast tumors. (a) $\mathrm{CD} 45^{+}$immune cells and E-selectin ${ }^{+}$ inflamed vessels in human breast tumors that were treated with DOX containing neoadjuvant chemotherapy. Representative images of double immunohistochemistry show CD45 (red), E-selectin (brown), and hematoxylin counterstaining (blue) in cases of residual and no residual tumor. The scoring index of CD45 and E-selectin were scored as 1 (minimal), 2 (moderate), or 3 (abundant). Score distribution was summarized as \%. Scale bar indicates $100 \mu \mathrm{m}$. (b) Immunohistochemistry of CD45 of DOX-treated tumors in the WT and E-selectin ${ }^{-/-}$mice. $4 \mathrm{~T} 1$ tumor-bearing mice $(n=5)$ were treated with saline or $0.5 \mathrm{mg} / \mathrm{kg}$ DOX (DOX0.5). $\mathrm{CD}^{+} 5^{+}$cells were counted from 3 representative images of 5 individual tumors and summarized as \% of $\mathrm{CD} 45^{+}$cells per field of view at a final magnification of $\times 200$. Scale bar indicates $100 \mu \mathrm{m}$. Graph is depicted as mean \pm SE. Statistical significance was analyzed by the Mann Whitney test. (c) Tumor growth rate of DOX-treated E-selectin ${ }^{-1-}$ and WT mice bearing $4 \mathrm{~T} 1$ tumors. ${ }^{*} p<0.05 ;{ }^{* *} p<0.01$.

\subsection{Binding of E-Selectin Aptamer to Inflamed Tumor Vessels}

An anti-E-selectin aptamer (ESTA) was developed for functional blockade of E-selectin (Figure 2a) [21]. Incubation of Cy3-labeled ESTA $(50 \mathrm{nM})$ with breast tumors derived from humans and MMTV-PyMT transgenic mice displayed intense, localized binding (red fluorescence) to vessels that co-localized with CD31 (green fluorescence) as shown in yellow overlay (Figure 2b). In contrast, Cy3-labeled ESTA binding to the vessels was absent in respective normal counterparts in both mice and humans. Similarly, Cy3-ESTA showed no notable binding to vessels in other healthy organs (data not shown). Additionally, neutralization of E-selectin with monoclonal antibody completely abolished subsequent Cy3-labeled ESTA binding to tumor vessels in serial sections from a human breast tumor (Figure 2c). Normal IgG control did not affect subsequent Cy3-labeled ESTA binding to the vessels, providing evidence of E-selectin specific binding in both mouse and human breast carcinomas without non-specific binding to normal vessels. To further determine the ability of ESTA to inhibit E-selectin function, the shear resistant adhesion assay was performed using human peripheral blood mononuclear cells (PBMCs) to E-selectin inducible tet-on human microvascular endothelial cells (ES-HMVECs) under physiologic flow. Induction of E-selectin expression by doxycycline resulted in a 25.8-fold increase in shear resistant adhesion of PBMCs to ES-HMVECs as 
shown by arrows, compared to baseline without induced E-selectin expression (Figure 2d). However, ESTA (100 nM) completely abrogated E-selectin-dependent shear resistant adhesion. The adhesion of PBMCs was unaffected by the control aptamer (CtrlTA). ESTA showed no effect on the viability of PBMCs, Jurkat cells, HL60 cells (Supplementary Figure S4), and HMVECs [21]. These data support the ability of ESTA for specific binding to E-selectin expressing vessels and blockade of immune cell adhesion onto the endothelial surface.

(a)

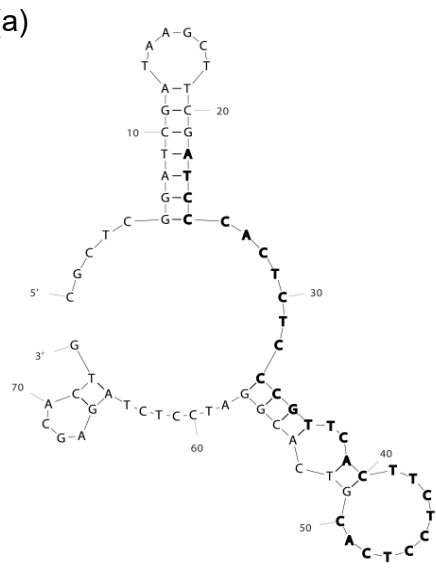

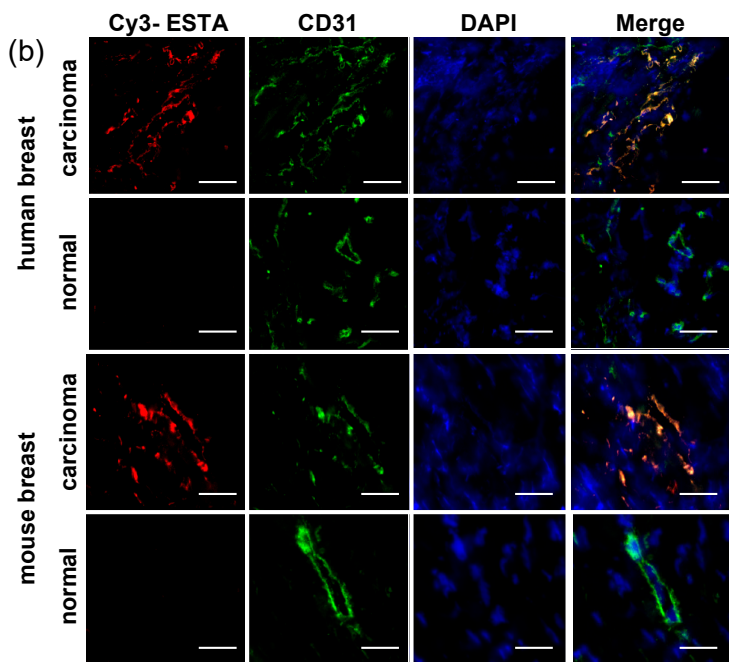

(d)

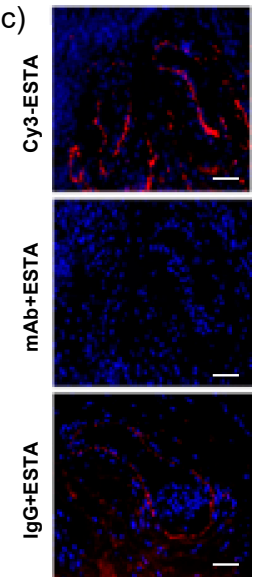

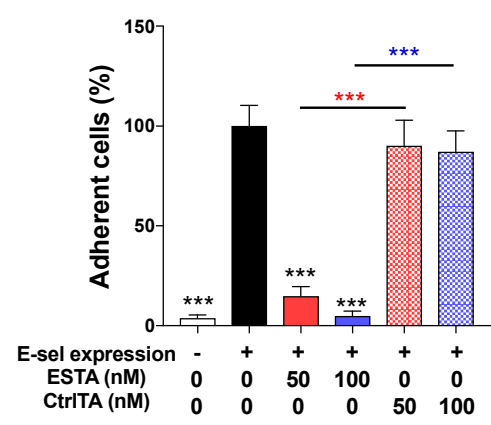
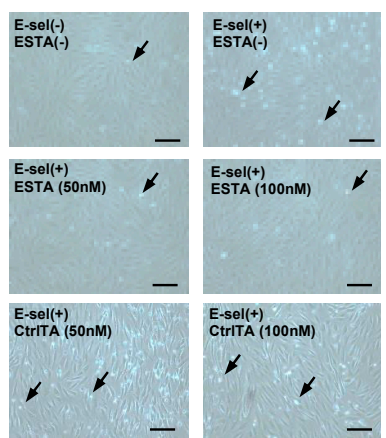

Figure 2. Binding of ESTA to E-selectin expressing vessels in the tumor. (a) M-fold structure of ESTA. (b) ESTA binding to the vessels in human and mouse breast tumors. Frozen section of human breast tumors $(n$ $=3$ ) and normal breast tissues $(n=2)$, mouse breast tumors derived from MMTV-PyMT $(n=6)$, and normal mammary fat pad from non-carrier control female mice $(n=6)$ were incubated with $50 \mathrm{nM}$ Cy3-labeled ESTA (red) and then immunostained with CD31 (green). The nucleus was counterstained with DAPI (blue). Images were captured in the same condition at a final magnification of $\times 400$. Scale bar indicates $10 \mu \mathrm{m}$. (c) ESTA binding to E-selectin expressing vessels in human breast tumors. Serial frozen sections of human breast tumors were incubated with either saline, E-selectin monoclonal antibody, or IgG control before incubation with $50 \mathrm{nM}$ Cy3-labeled ESTA (red) and counterstain with DAPI (blue). Representative images were taken at a final magnification of $\times 200$. The scale bar indicates $50 \mu \mathrm{m}$. (d) Flow adhesion assay of PBMCs to E-selectin expressing ES-HMVECs. Following induction of E-selectin expression by doxycycline, the cells were treated with either saline, ESTA, or CtrlTA (50 or $100 \mathrm{nM}$ ) for $1 \mathrm{~h}$. A pool of human PBMCs $\left(1.5 \times 10^{6}\right.$ cells $\left./ \mathrm{mL}\right)$ was infused into a flow chamber for $3 \mathrm{~min}$ at $1 \mathrm{dyn} / \mathrm{cm}^{2}$. Arrows in representative images indicate PBMCs that adhered to ES-HMVECs at 100 $\times$ magnification. Data from the doxycycline-incubated, untreated group was shown as $100 \%$. The data represent mean \pm SD from at least a duplicate of three independent experiments, and statistical significance was determined by the Mann Whitney test. ${ }^{* * *} p<0.001$. The scale bar indicates $50 \mu \mathrm{m}$. 


\subsection{ESTA Enhanced the Anti-Tumor Effect of DOX}

We next examined whether ESTA improves the anti-tumor effect of DOX. Female MMTV-PyMT mice were treated once weekly with two doses of DOX (high, $2.5 \mathrm{mg} / \mathrm{kg}$; low, $0.5 \mathrm{mg} / \mathrm{kg}$ ), followed by twice weekly with either ESTA or CtrlTA once the tumor reached $200 \mathrm{~mm}^{3}$ as shown in the treatment scheme. Two weeks treatment with high dose DOX significantly delayed tumor growth, whereas low dose DOX treatment showed no significant anti-tumor effect (Figure 3a). A combination of ESTA with low dose DOX significantly reduced the tumor growth rate compared to the same dose DOX alone (Figure 3a and Supplementary Figure S5a,b). High dose DOX/ESTA combination demonstrated sustainable tumor growth inhibition over 2 weeks compared to DOX alone. The tumor volume of low dose DOX/ESTA treated mice was similar to that of high dose DOX-treated ones (Supplementary Figure S5b), accounting for an approximately 5 -fold dose reduction. ESTA alone, however, showed no effect on tumor growth (Supplementary Figure S5d). These studies suggested that ESTA intensifies the anti-tumor effect of DOX, but by itself has no effect on tumor growth in mice. Additionally, a lack of effect of CtrlTA indicates that the effect of ESTA is not due to a non-specific effect of the nucleic acid on the immune response (Figure 3a). The high dose DOX/ESTA combination significantly reduced lung metastases compared to DOX alone (1.83 vs. 0.13 metastatic colonies per $\mathrm{cm}^{2}$; Figure $3 \mathrm{~b}$ ). No obvious weight loss was noted in any treatment group in MMTV-PyMT mice (Supplementary Figure S5c). Notably, the IC I0 $_{50}$ DOX was unchanged by the addition of ESTA $(1.02 \mu \mathrm{M}$ in DOX alone vs. $1.45 \mu \mathrm{M}$ in DOX/ESTA; Figure 3c); thus, a synergy between DOX and ESTA on tumor growth inhibition was not due to the enhancement of DOX cytotoxicity, suggesting, rather, indirect effects. The density of CD45 immune cells in the tumor stroma, excluding necrotic areas and peripheral stroma, was 2.0- and 3.4-fold higher in low and high dose DOX-treated turmors, respectively, compared to tumors in the saline control group (Figure 3d). However, $\mathrm{CD} 45^{+}$immune cell density was far less in DOX/ESTA-treated tumors than those treated with the same dose of DOX in MMTV-PyMT mice (Figure 3d), suggesting that ESTA may mitigate DOX-induced CD $45^{+}$immune cell infiltration.

(a)
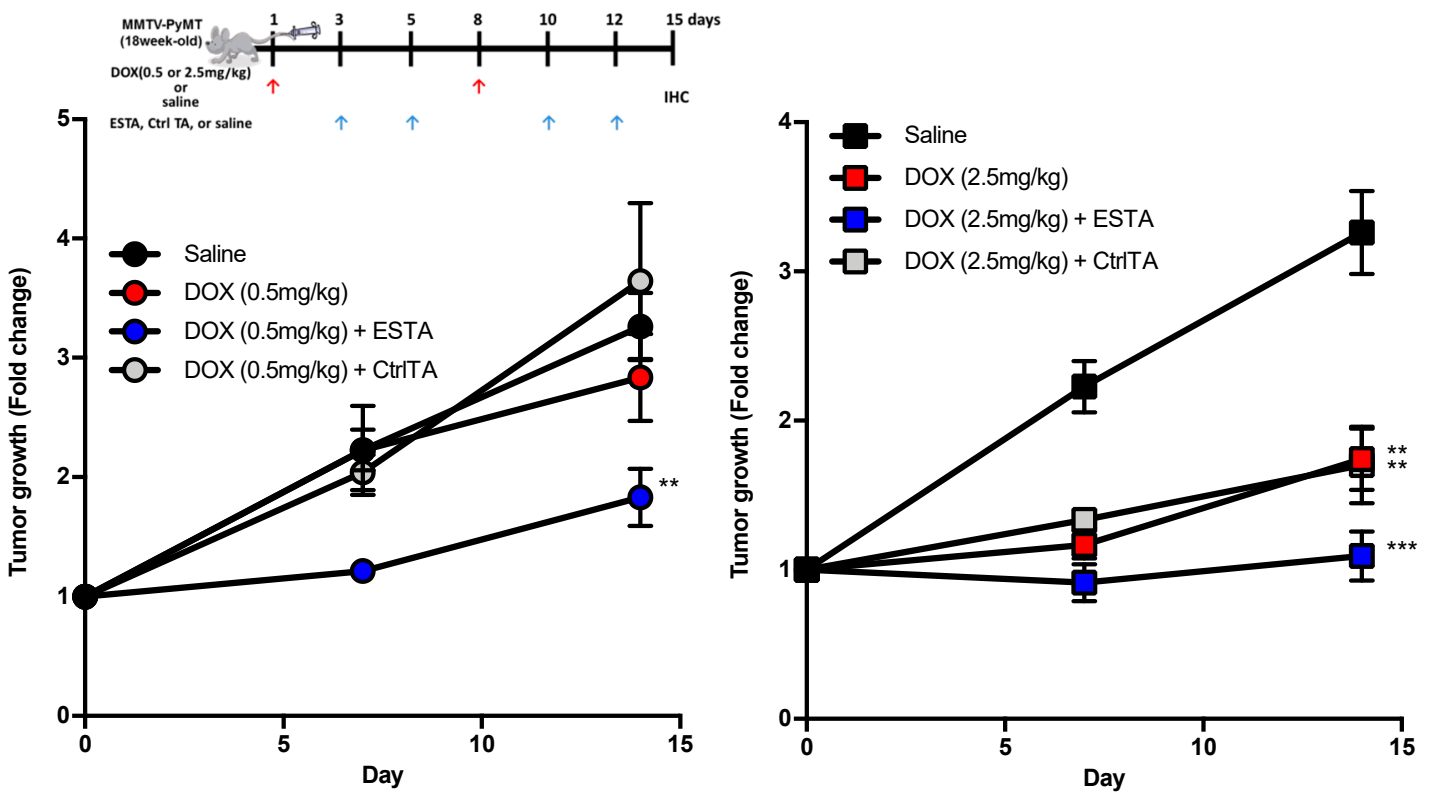

Figure 3. Cont. 
(b)

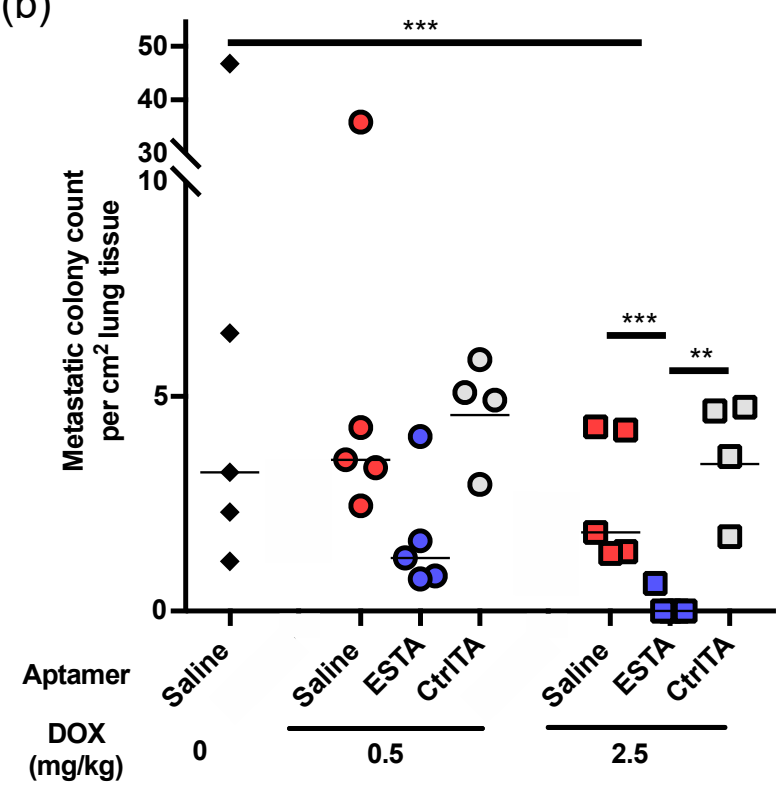

(c)

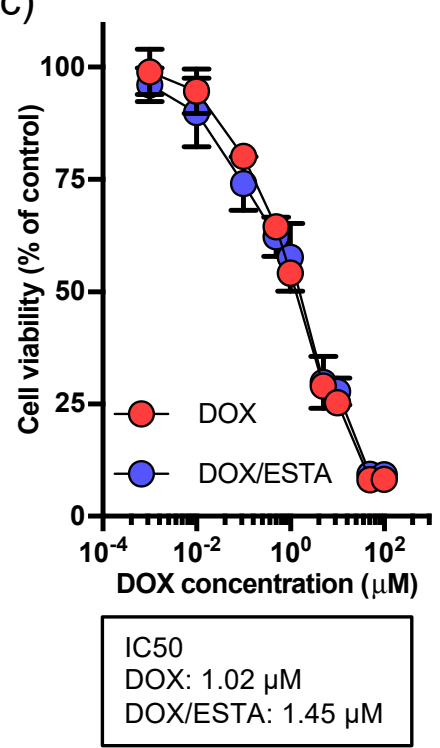

(d)

Ctrl

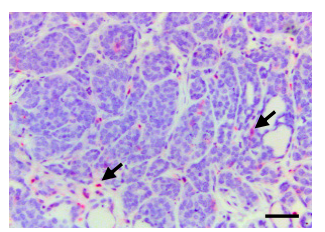

DOX0.5
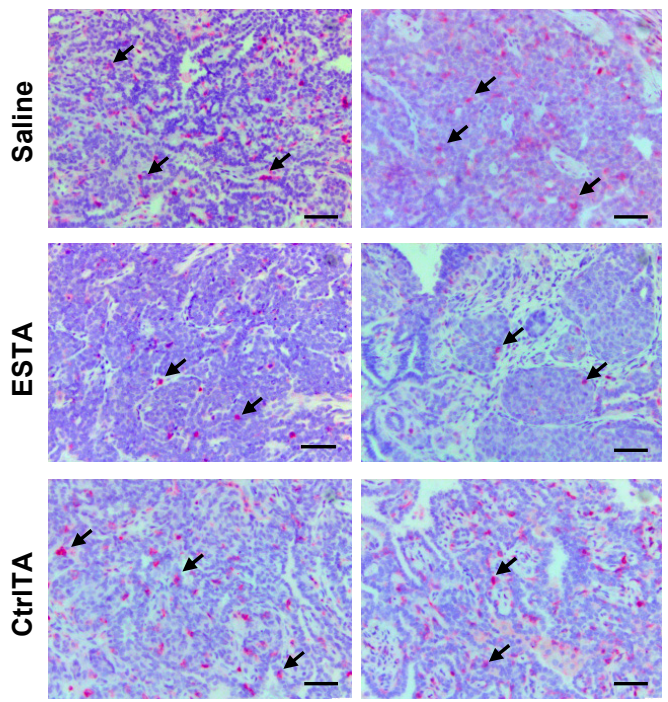

DOX2.5
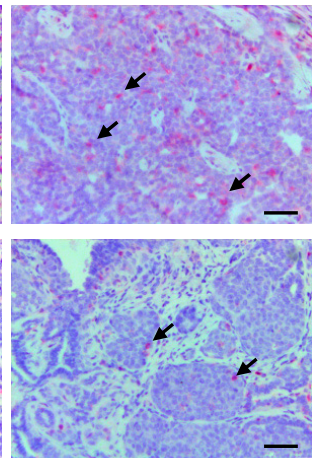

Figure 3. The effect of ESTA on DOX therapy. (a) Tumor growth in MMTV-PyMT mice. Mice $(n=6)$ were treated with DOX ( 0.5 or $2.5 \mathrm{mg} / \mathrm{kg}$ ), DOX/ESTA, or DOX/CtrlTA for 2 weeks as depicted in the timeline. The graph shows fold change of tumor growth (0 days/treatment starting point as 1 of each group at days 0, 7, and 14. (b) The effect of ESTA/DOX combination on lung metastases. Step sections of the whole lung were stained with H\&E and metastatic foci sizes of $>50 \mu \mathrm{m}$ ф were counted and normalized by total area $\left(\mathrm{cm}^{2}\right)$. (c) The effect of ESTA on IC50 of DOX. Py8119 cells were incubated with various concentration of DOX $(0.001,0.01,0.1,1,10,100 \mu \mathrm{M})$ with saline or ESTA $(100 \mathrm{nM})$ for $24 \mathrm{~h}$. Cell viability was measured by MTT assay $(n=6)$. The viability of saline-treated cells was $100 \%$. $\mathrm{IC}_{50}$ was calculated by four parameter logistic curves. (d) Immunohistochemistry of CD45. Tumors were stained with CD45 (red) and counterstained with hematoxylin (blue). Arrows indicate CD45 ${ }^{+}$cells. The bar graph depicts mean $\pm \mathrm{SE}$, and statistical significance was analyzed by the Mann Whitney test. Scale bar indicates $50 \mu \mathrm{m}$. Graph is depicted as mean \pm SE $(a, b)$ or \pm SD (d). Statistical significance was analyzed by the Mann Whitney test. ${ }^{*} p<0.05 ;{ }^{* *} p<0.01$; ${ }^{* * *} p<0.001$. 


\subsection{ESTA Suppressed DOX Treatment-Associated $T_{H} 2$ Shift}

Since the enhanced anti-tumor effect of the DOX/ESTA combination was accompanied by a profound decrease in intratumoral $\mathrm{CD}^{+} 5^{+}$density, we next performed multicolor flow cytometry (FACS) to identify the affected immune cell subsets (Supplementary Figure S6). Weekly DOX treatment resulted in an approximately 2 -fold increase of $\mathrm{CD}^{+}, \mathrm{CD}^{+}$, and $\mathrm{CD} 8^{+} \mathrm{T}$-lymphocytes in py8119 tumors (Figure 4a). However, DOX/ESTA treatment resulted in a reduction of T-lymphocyte proportions to a level similar to saline control (Figure 4a). While proportion of $\mathrm{CD}^{+}, \mathrm{CD}^{+}$, and $\mathrm{CD} 8^{+}$ T-lymphocytes increased with DOX treatment, the CD4/CD8 ratio was unaffected among treatment groups. Furthermore, T-lymphocytes subset analysis of a pool of tumors showed that DOX treatment results in a $\mathrm{T}_{\mathrm{H}} 2$ shift, which was suppressed by ESTA (Figure $4 \mathrm{~b}$ ). Further analysis of intratumoral macrophage subsets showed that DOX treatment resulted in an increase of M2 TAM proportion $\left(\mathrm{CD} 45^{+}\right.$ F4/80+ CD11b+ Ly6Clow Ly6Glow MHC II $\left.{ }^{\text {low }}\right)$ with no significant changes in M1 TAM (CD45 ${ }^{+}$F4/80+ CD11b+ Ly6Clow Ly6Glow MHC II ${ }^{\text {hi }}$ ) in MMTV-pyMT mice, skewing tumors towards the M2 state, while ESTA suppressed this change (Figure 4c). Consistently, histopathologic analysis supported a 2.1- and 1.8-fold increase in F4/80 $0^{+}$TAMs and $\mathrm{CD} 163^{+} \mathrm{M} 2$ TAMs in DOX-treated mouse tumors, respectively, compared to saline controls (Figure 4d). However, ESTA suppressed this change, to a level slightly lower than that in saline controls. Based on the profound changes noted in $\mathrm{CD} 45^{+}$density in histologic analysis (Figure 3), the extent of proportional changes in immune subsets shown in FACS analysis was presumably attenuated as the data was normalized by CD45.
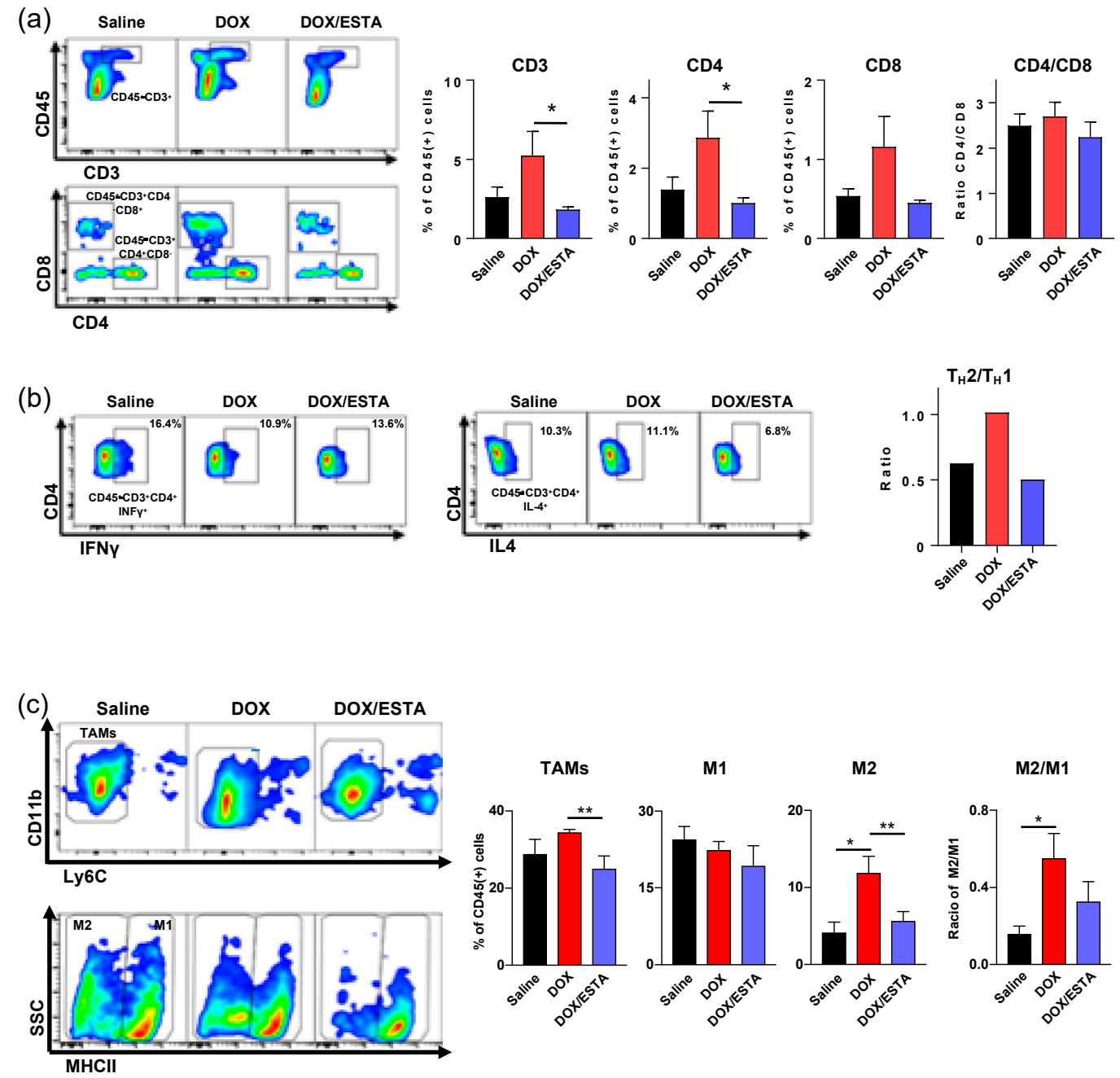

Figure 4. Cont. 
(d)

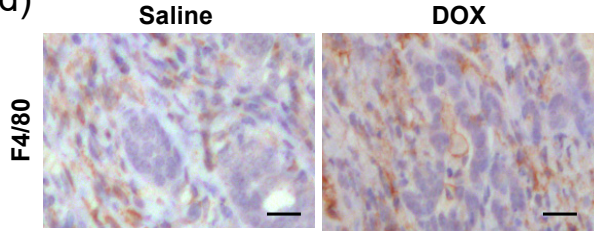

DOX/ESTA
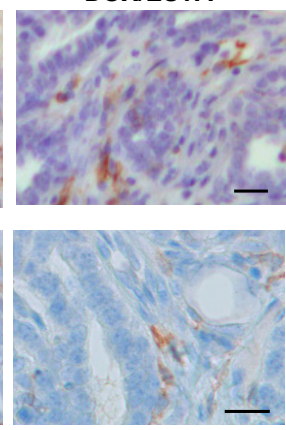
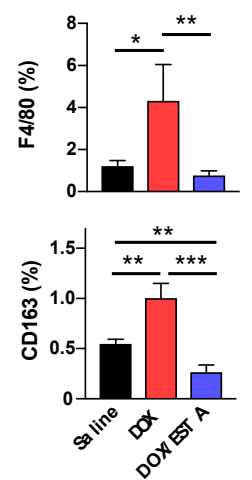

Figure 4. Suppression of immune cell infiltration by ESTA in DOX-treated tumors. (a) FACS analysis of TILs in tumors derived from py8119 cells. The data were depicted as mean \pm SE and analyzed by the Student's T-test. (b) Analysis of TIL subsets. A pool of tumors $(n=6)$ analyzed by FACS for $\mathrm{T}_{\mathrm{H}} 1$ and $\mathrm{T}_{\mathrm{H}}$ 2, following activation. (c) FACS analysis of TAMs in breast tumors of MMTV-pyMT mice. The data are depicted as mean \pm SE and analyzed by the Student's T-test. ${ }^{*} p<0.05 ;{ }^{* *} p<0.01$. (d) Immunohistochemistry of TAMs. Representative images show overall TAMs (F4/80) and M2 TAMs (CD163) in brown and the nucleus in blue. Graphs summarize TAMs and M2 TAMs in stromal area (cells / stromal area $\mathrm{mm}^{2}$ ) at a final magnification of $\times 200$. Scale bar indicates $20 \mu \mathrm{m}$. The cells were counted from three representative images of six individual tumors. Statistical significance was analyzed by the Student's T-test. ${ }^{*} p<0.05 ;{ }^{* *} p<0.01 ;{ }^{* *} p<0.001$.

\subsection{ESTA Suppressed $T_{H}$ 2-Related Pro-Tumorgenic Changes}

Given the suppression of the DOX-associated $\mathrm{T}_{\mathrm{H}} 2$ shift by ESTA, histopathologic analyses were performed using MMTV-pyMT tumors to evaluate $\mathrm{T}_{\mathrm{H}}$ 2-releated pro-tumorigenic changes [22]. Significantly increased expression in $\alpha$-SMA (16 fold), SDF-1 (2.1 fold), TGF $\beta$ (2.0 fold), and CD31 (1.5 fold) were noted in DOX-treated tumors compared to saline control (Figure 5a). However, ESTA suppressed DOX-associated pro-fibrotic and pro-angiogenic changes. DOX treatment resulted in a reduction in Ki67 (11 fold) regardless of the presence of ESTA, compared to saline control. To further validate DOX treatment-associated fibrotic changes, quantitative and qualitative changes in interstitial collagen were determined using surgically resected invasive human breast tumors that were treated with DOX containing chemotherapy and their matched biopsy tumors (Stage II-III). Bright field images of pre-treatment tumors showed extensive collagen fibrils randomly dispersed in between cancer cell clusters. In contrast, residual breast tumors showed more abundant collagen fibers bordering cancer cell clusters (Figure 5b). Polarized images confirmed a marked increase in collagen linearity, length, and thickness in residual human breast tumors. Semi-quantitative analysis revealed a steep increase in orthogonal collagen among residual tumors (i.e, post-treated) compared to their matched biopsy tumors (pre-treated; 0.6 vs. 11.8). In conclusion, our study demonstrated that suppression of DOX-associated de novo infiltration of immune cells through E-selectin functional blockade mitigates $\mathrm{T}_{\mathrm{H}} 2$ shift, pro-tumorigenic, and pro-fibrotic changes (Figure 6). 
(a)
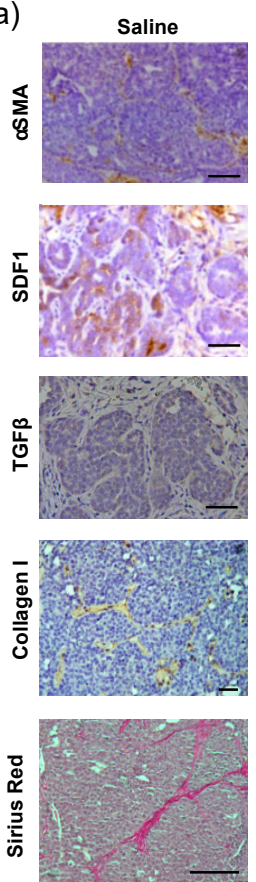

ồ
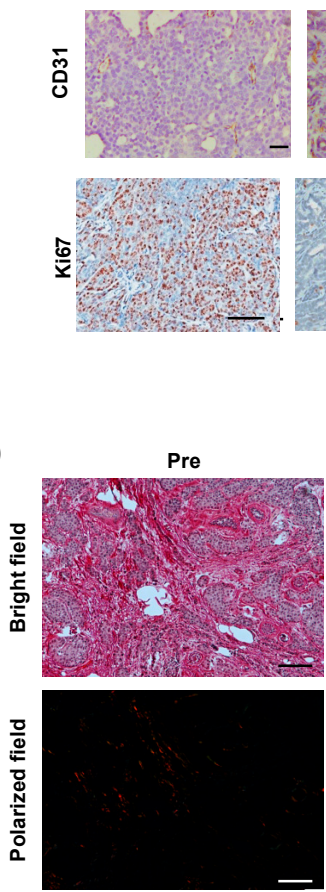

(b)
DOX
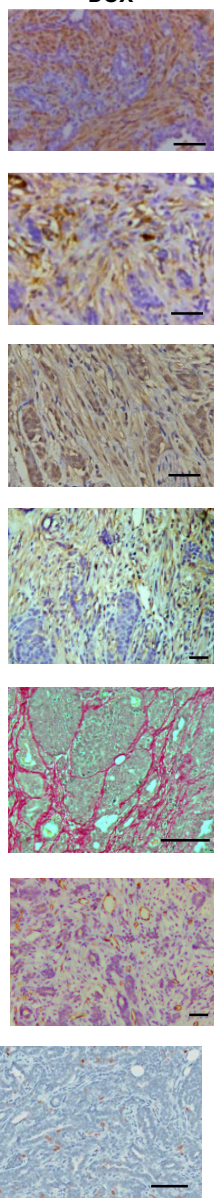

DOXIESTA
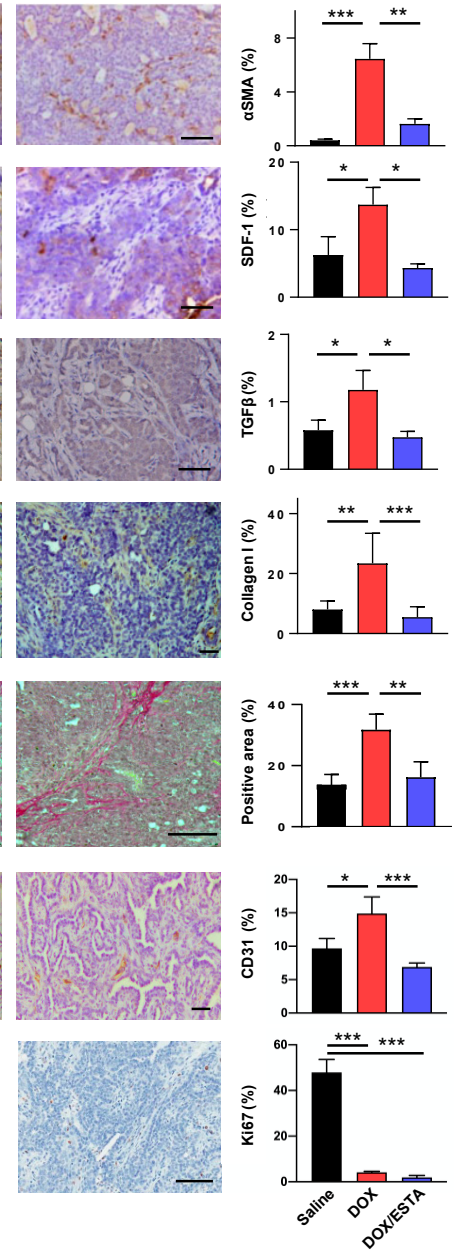
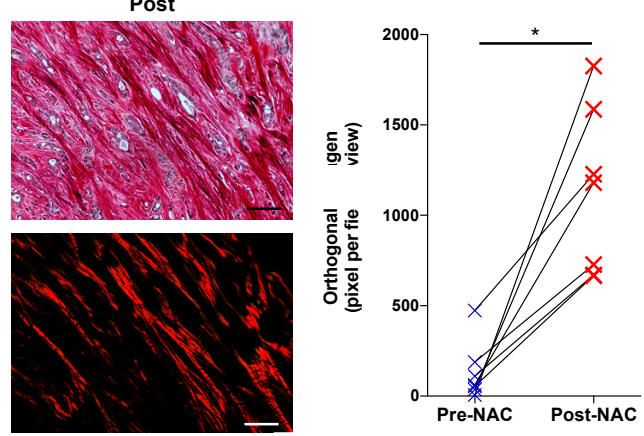

Figure 5. ESTA suppressed DOX-induced pro-tumorgenic changes. (a) Immunohistochemical analysis of tumor stroma components. MMTV-PyMT breast tumors $(n=6)$ treated with saline, DOX, or DOX/ESTA were analyzed. Five representative images were taken from each mouse and quantified as $\%$ of stromal area $\left(\mathrm{mm}^{2}\right)$. Scale bar indicates $50 \mu \mathrm{m}$. The data were summarized in the graph as mean \pm SE. Statistical significance was analyzed by Student's T-test. ${ }^{*} p<0.05 ;{ }^{* *} p<0.01 ;{ }^{* * *} p<0.001$. (b) Elevated collagen deposition in DOX treated surgically resected residual human breast tumors (post-treatment) and their matched biopsy tumors (pre-treatment) were stained with Picro-Sirius Red and counterstained with Weigert's hematoxylin $(n=7)$. Representative images captured by bright-field (parallel) and polarized light (orthogonal collagen) are shown. Orthogonal collagen was measured as the percentage of total unmasked pixels except perivascular in the field of view at a final magnification of $\times 100$. Scale bar indicates $100 \mu \mathrm{m}$. The graph depicted individual cases of orthogonal collagen preand post-treatment. Data were analyzed by the Kruskal-Wallis test, ${ }^{*} p<0.05, \mathrm{Cl}=95 \%$. 

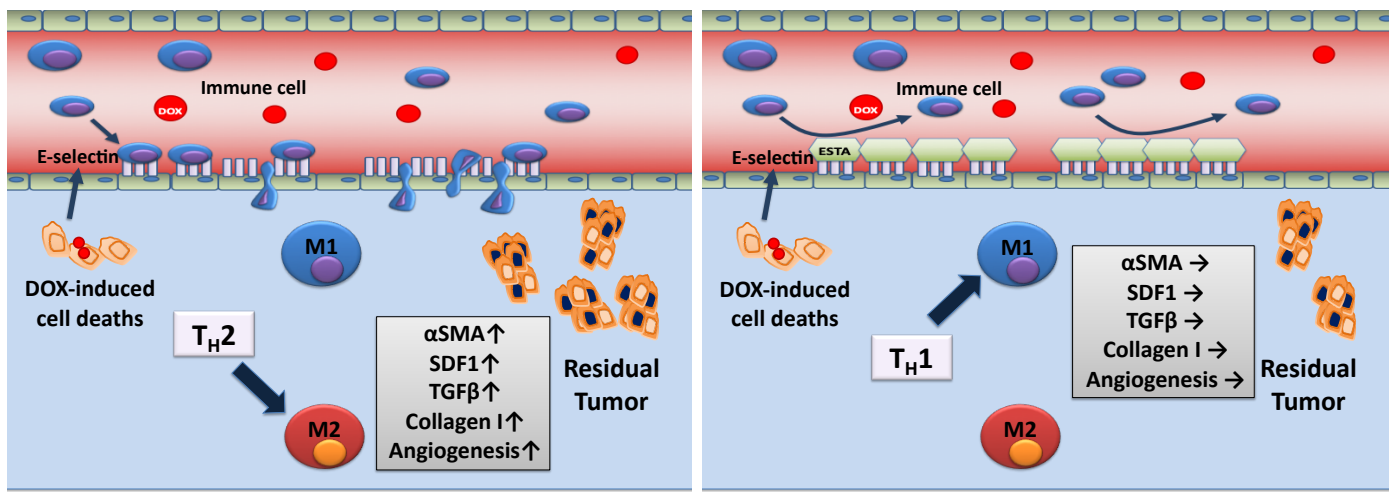

Figure 6. Schematic working model of ESTA's mechanism of action. DOX-induced cell death provokes infiltration of immune cells through E-selectin expressing inflamed vessels, skewing the tumor towards $\mathrm{T}_{\mathrm{H}}$ 2. $\mathrm{T}_{\mathrm{H}} 2$ cytokines induce pro-tumorigenic (proliferation and angiogenesis) and pro-fibrotic changes. The binding of ESTA to E-selectin expressing vessels obstructs the adhesion of immune cells to the luminal surface of vessels, subsequently suppressing DOX treatment-induced pro-tumorigenic and pro-fibrotic changes.

\section{Discussion}

Anthracyclines (e.g., doxorubicin: DOX) are commonly integrated into first-line chemotherapy regimens and indicated for many types of cancer, including breast cancer. Cell death instigates successive and sequential recruitment of a large number of circulating immune cells shortly after DOX administration [12]. Accordingly, increased immune cell infiltration and composition changes have been detected in chemotherapy-treated residual breast tumors in both mice and humans $[6,10,11]$. Our study showed a substantial increase of $\mathrm{CD} 5^{+}$cells in DOX-treated residual mouse and human breast tumors. A recent study indicated that abundant TILs and TAMs in post-chemotherapy residual breast tumors are associated with shorter disease-free progression time [8], suggesting a possible inverse association between therapy-induced immune cell infiltration and therapeutic response. Functional blockade of E-selection, a gateway for infiltrating immune cells into damaged tissues, using genetic ablation and ESTA markedly reduced tumor growth rate when combined with DOX. ESTA was neither cytotoxic by itself nor an enhancer of DOX cytotoxicity, rather, administration of ESTA allowed an approximately five-fold reduction in dose of DOX to achieve equal therapeutic effect perhaps through the indirect effect of suppressing the DOX treatment-associated $\mathrm{T}_{\mathrm{H}} 2$ shift. Anthracycline-induced cardiomyopathy, including oxidative stress [23-25], IL-1-mediated inflammation [23,26-28], and cardiac apoptosis [23,24], limits the allowable cumulative lifetime dose; thus, reduction of DOX dosage while maintaining efficacy is an attractive therapeutic strategy. ESTA blocked de novo infiltration of CD45 $5^{+}$ cells and the $\mathrm{T}_{\mathrm{H}} 2$ shift in the DOX-treated tumors; however, the effect of DOX/ESTA on other ogans remains unaddressed. The outcomes of $\mathrm{T}_{\mathrm{H}} 1$ dominance in the tumor vs. other organs, particularly the heart, are expected to be different, given the role of IL-1 in DOX-associated cardiac toxicty [29]. Therefore, further comprehensive analyses including immunoprofiles and cytokine panel in other organs necesitate a full evaluation to understand the benefit of ESTA therapy.

Theoretically, blockade of tissue infiltration of immune cells is attainable through targeting a key mediator in the adhesion cascade (i.e., immune cells, cytokines/chemokines, or vessels). Thus far, immune cells ( $\alpha 4$ integrin [30] or CD11b/CD18 [31]) and chemokines (macrophage colony stimulating factor receptor (CSF1R [32]) have been successfully targeted by monoclonal antibodies for impediment of immune cell infiltration into tumors or other tissues. These antibodies, in combination with chemotherapy or radiation, enhanced the therapeutic response in murine models of breast cancer $[6,31]$. Consistent with findings from the previously mentioned studies, targeting the adhesion cascade via E-selectin expressing vessels using ESTA provides additional evidence for the validity of anti-migration strategy in conjunction with DOX. Implementation of an anti-migration therapy, however, may require 
careful considerations of the potential for compensatory influx of other immune cell subsets into the tumor [33], impairment of immunosurveillance, infection, delay of wound repair, and so on. Thus, it is critical to establish a stratgegy for patient stratification and treatment scheduling (e.g., duration and administration sequence with chemotherapy). Given the pivotal role of E-selectin as a mediator of tissue migration and its spatiotemporally limited expression on the luminal surface of inflamed vessels, different chemical entities of antagonistic ligands have been developed [21,34-38].

Advantages of aptamers over antibodies or small molecule inhibitors may include low or no immunogenicity [39,40], high tolerability [41], low production cost, and long shelf-life [42], while nuclease sensitivity [43,44], rapid renal clearance [44,45], and interactions with serum components [46] collectively contribute to a common shortcoming of aptamers, their short serum half-life. In this line, daily intravenous administration of ESTA was necessary to achieve the tumor growth inhibition due to the rapid clearance of unmodified ESTA, although this dosing schedule was well tolerated in mice [47]. The biodistribution of an intravenously injected aptamer largely differs by target, and tissue uptake of the aptamer in normal organs except for kidneys and liver, is generally low [48]. The improvement of pharmacokinetic and pharmacodynamic properties is essential for successful clinical translation of aptamer therapeutics.

In summary, our study showed a reduction of immune cell influx through blockade of E-selectin readily suppresses DOX-induced $\mathrm{T}_{\mathrm{H}} 2$ shift and fibrosis, highlighting the potential advantage of controlling DOX-induced immune cell infiltration and presenting an opportunity for supportive care in combination with DOX that could potentially improve outcomes and reduce adverse effects in BC treatment.

\section{Materials and Methods}

\subsection{Clinical Samples}

Stage II-III breast cancer patients were consented to a study approved by the IRB committee of the University of Oklahoma Health Sciences Center from 2014-2016. Formalin-fixed paraffin-embedded (FFPE) whole mount tissue sections of surgically resected tumors following DOX-containing neoadjuvant chemotherapy (AC-T) were used for immunohistochemistry. PBMCs were collected from the whole blood of healthy donors $(n=3)$. Frozen sections of breast tumors $(n=3)$ were retrieved from the tissue archive at Thomas Jefferson University from 2011-2012. Frozen sections of normal tissues were purchased from US Biomax (Derwood, MD, USA).

\subsection{Cell Culture}

Murine breast cancer cell lines, 4T1 and py8119 (ATCC, Rockville, MD) were cultured in Dulbecco's modified Eagle medium (Corning, Corning, NY, USA) and RPMI, respectively, supplemented with 10\% fetal bovine serum (FBS), 1\% glutamax, and 1\% antibiotic-antimycotic (Thermo Fisher Scientific, Waltham, MA, USA). MITO extender was added to py8119 cells (BD Bioscience, San Jose, CA, USA). E-selectin inducible tet-on human microvascular endothelial cells (ES-HMVEC) were cultured in endothelial basal medium-2 (EBM-2) (Lonza, Basel, Switzerland) supplemented with 2\% tet-approved FBS (Clontech Laboratories, Mountain View, CA, USA) and EGM SingleQuot Kit containing epidermal growth factor (EGF), hydrocortisone, and GA-1000 (Lonza). E-selectin expression was induced with $1000 \mu \mathrm{g} / \mathrm{mL}$ of doxycycline for $5 \mathrm{~h}$ as described previously [49]. All cells were cultured in $5 \% \mathrm{CO}_{2}$ humidity chambers at $37^{\circ} \mathrm{C}$.

\subsection{Aptamer Binding to Tumor Vasculature}

ESTA (5'-CGCTCGGA*TCGA*TA*A*GCTTCGA*TCCCA*CTCTCCCGTTCA*CTTCTCCTCA $\left.{ }^{*} \mathrm{CGTCA}^{*} \mathrm{CGGA}^{*} \mathrm{TCCTCTA}{ }^{*} \mathrm{GA}^{*} \mathrm{GCA}^{*} \mathrm{CTG}-3^{\prime}\right)$ and CtrlTA (5'-CCCACTTA*TCGTCCCTTAA ${ }^{*}$ TGA $^{*}$ GTTTA $^{*}$ CTCGCA*CACCGGACAGCCGTCGGATGGCTGGATCCG*TAGCGGTCCGG-3') were synthesized chemically and purified as described previously (asterisks indicate adenines with 
monothiophosphate substitution) [21,50]. The tissue sections were fixed with $4 \%$ paraformaldehyde and incubated with $50 \mathrm{nM}$ Cy3-labeled ESTA, then immunostained with anti-CD31 antibody and counterstained with DAPI. For antibody blocking, serial sections were pre-incubated with E-selectin antibody or IgG control before incubation with Cy3-labeled ESTA.

\subsection{Immunohistochemistry}

Histopathologic analysis was performed on FFPE sections $(4 \mu \mathrm{m})$. Double immunohistochemistry for E-selectin and CD45 in human breast carcinoma was performed as previously described [51]. The background was corrected through immunohistochemistry by replacing antibody with IgG. Slides were evaluated by a board-certified pathologist (RZ). E-selectin vascular expression was graded as 1 (none to weak), 2 (modest), or 3 (high). Immunohistochemical staining of CD45 was quantitatively categorized as a score of 1 ( $\leq 30$ cells), 2 (31 to 100$)$, or $3(>100) C D 45^{+}$cells around residual tumors containing invasive cells in the field of view, respectively. Metastatic foci present in mouse lung were counted from all lobes and normalized by tissue area. All images were captured with a Leica DM2500 microscope connected to a Leica DFC425C camera (Leica, Wetzlar, Germany). All slides were scanned and quantified using Aperio (Leica). For immunohistochemistry of mouse tumors, after deparaffinization and rehydration, antigen retrieval was performed using Envision Flex Target Retrieval Solution ( $\mathrm{pH}$ 6.1, Dako, Santa Clara, CA, USA) in a pressure cooker for $20 \mathrm{~min}$ at $110{ }^{\circ} \mathrm{C}$. Endogenous peroxidase and nonspecific epitopes were blocked with $0.3 \%$ hydrogen peroxide. Sections were incubated with the primary antibody followed by the corresponding secondary antibody as listed in Supplementary Figure S7. Expression of CD45 and other markers was visualized using aminoethylcarbazole and 3,3-diaminobenzidine, respectively, followed by counterstain with CAT Hematoxylin (Biocare Medical, Pacheco, CA, USA). The number of positive cells in five randomly selected high-power fields exclusive of necrotic areas and non-peripheral stroma at $\times 200$ magnification were counted and normalized by field of view of area of interest (stroma or cancer cells).

\subsection{Adhesion Assay}

ES-HMVECs were grown to confluence in a flow chamber ( $\mu$-Slide I 0.4 Luer; Ibidi, Madison, WI, USA) coated with collagen and fibronectin as described previously [49]. After incubation with $1000 \mathrm{ng} / \mathrm{mL}$ doxycycline for $5 \mathrm{~h}$, a pool of human PBMCs $\left(5 \times 10^{5} / \mathrm{mL}\right)$ was infused into a flow chamber at one dyn $/ \mathrm{cm}^{2}$ shear stress for $5 \mathrm{~min}$.

\subsection{Mouse Models}

Mice were obtained from the Jackson Laboratory (Bar Harbor, ME, USA) and maintained in a pathogen-free facility. For syngeneic grafting tumor models, 4T1 cells were injected into the abdominal mammary fat pads of 6 week-old female E-selectin ${ }^{-/}$or WT Balb/c mice. Py8119 cells were injected into the mammary fat pad of C57BL/6J as the cells were originated from B6.FVB-Tg (MMTV-PyVT) 634Mul/LellJ. Treatment was initiated when tumor volume reached approximately $100 \mathrm{~mm}^{3}$ as indicated in the schedule timeline. B6.FVB/MMTV-PyMT (MMTV-PyMT) were bred, and females were maintained until tumor size reached $250 \mathrm{~mm}^{3}$ on either thoracic or abdominal fat pad. All mice were intravenously administered saline, DOX, or aptamer via the tail vein. Control mice received equivolume of saline for equal manipulation frequency. Tumor size was measured by caliper, and volume was calculated using the formula, $\mathrm{L} \times \mathrm{W}^{\wedge} 2 \times 0.52$, where $\mathrm{L}$ is the long diameter, and $\mathrm{W}$ is the short perpendicular diameter.

\subsection{Preparation of Intratumoral Immune Cells and Flow Cytometry}

A single cell suspension from mouse tumors was prepared and subjected to FACS analysis [52]. Briefly, mouse tumors were cut into small pieces, treated with collagenase A, and filtered through a $70 \mu \mathrm{m}$ strainer. Leukocytes were isolated by using Fico/Lite LymphoH density gradient sedimentation (Atlanta Biologicals, Lawrenceville, GA, USA). Cells were incubated with Zombie Aqua viability kit 
(Biolegend, San Diego, CA, USA) to stain dead cells and Fc-block (Biolegend) to prevent nonspecific binding. Cell membrane antigens were stained with antibodies described in Supplementary Figure S7. The cells were analyzed using a BD LSRII analyzer. Data were acquired using BD FACSCanto II (BD Biosciences, San Jose, CA, USA) and FlowJo software version 10 (Tree Star, Ashland, OR, USA).

\subsection{Statistical Analysis}

Data obtained from in vitro experiments were statistically analyzed to provide $95 \%$ power for test at a significance level of 0.05 . The results are presented as mean $\pm \mathrm{SD}$ for in vitro and mean \pm SEM for in vivo experiments, respectively. Comparisons between two groups were analyzed using Student's t-test (in vitro) or Mann Whitney test (in vivo) by Prism 7 software (GraphPad Software, La Jolla, CA, USA).

\section{Conclusions}

This study suggests that DOX treatment instigates de novo intratumoral infiltration of immune cells through E-selectin, and functional blockade of E-selectin may reduce residual tumor burden as well as metastasis through suppression of $\mathrm{T}_{\mathrm{H}} 2$ shift. Anti-migration therapy to mitigate therapy-induced immune cell infiltration together with chemotherapy may present a promising strategy for improved outcomes in breast cancer treatment.

Supplementary Materials: The following are available online at http://www.mdpi.com/2072-6694/12/3/725/s1, Figure S1: Scoring index of CD45 and E-selectin., Figure S2: Demographic and clinical characteristics of DOX-containing neoadjuvant chemotherapy-treated (AC-T regimen) human breast carcinoma cases, Figure S3: Body weight measurement of mice assigned to Figure 1c study, Figure S4: The effect of ESTA on cell viability, Figure S5: Tumor growth and body weight measurements of MMTV-PyMT mice, Figure S6: Gates for FACS analyses, Figure S7: List of antibodies used for immunofluorescence/immunohistochemistry and FACS.

Author Contributions: Conceptualization, T.T.; methodology, T.T., Y.M., N.H. (Natalie Hills), G.L.R.L., Y.K. and D.E.V.; software, M.L., R.D., N.H. (Nafis Hasan), I.C.; validation, Y.M., H.K., L.G. and D.E.V.; formal analysis, M.L. and I.C.; investigation, Y.M., H.K., N.I., G.L.R.L., Y.K. and D.E.V.; resources, T.T., D.G.G.; data curation, Y.M., M.L.; writing-Original draft preparation, T.T., D.E.V., D.G.G., H.R.; writing-Review and editing, M.L., H.R., T.T, D.G.G., D.E.V.; pathology, R.Z.; supervision, T.T., D.V., D.G.G.; project administration, T.T., H.R., D.G.G., D.E.V.; funding acquisition, T.T. All authors have read and agreed to the published version of the manuscript.

Funding: This work was supported by the Department of Defense (W81XWH-11-1-0238 to T.T), the National Institutes of Health (1R01CA160271-01A1 to T.T), the American Cancer Society (IRG-08-060-04 to TT), and the Pennsylvania Breast Cancer Coalition (T.T).

Conflicts of Interest: The authors declare no conflict of interest.

\section{References}

1. Thompson, A.M.; Moulder-Thompson, S.L. Neoadjuvant treatment of breast cancer. Ann. Oncol. 2012, 23 (Suppl. S10), x231-x236. [CrossRef]

2. Carlson, R.W.; Allred, D.C.; Anderson, B.O.; Burstein, H.J.; Carter, W.B.; Edge, S.B.; Erban, J.K.; Farrar, W.B.; Goldstein, L.J.; Gradishar, W.J.; et al. Breast cancer. Clinical practice guidelines in oncology. J. Natl. Compr. Cancer Netw. 2009, 7, 122-192. [CrossRef] [PubMed]

3. Teshome, M.; Hunt, K.K. Neoadjuvant therapy in the treatment of breast cancer. Surg. Oncol. Clin. N. Am. 2014, 23, 505-523. [CrossRef] [PubMed]

4. Von Minckwitz, G.; Untch, M.; Blohmer, J.U.; Costa, S.D.; Eidtmann, H.; Fasching, P.A.; Gerber, B.; Eiermann, W.; Hilfrich, J.; Huober, J.; et al. Definition and impact of pathologic complete response on prognosis after neoadjuvant chemotherapy in various intrinsic breast cancer subtypes. J. Clin. Oncol. 2012, 30, 1796-1804. [CrossRef] [PubMed]

5. Sahoo, S.; Lester, S.C. Pathology of breast carcinomas after neoadjuvant chemotherapy: An overview with recommendations on specimen processing and reporting. Arch. Pathol. Lab. Med. 2009, 133, 633-642. [CrossRef] 
6. DeNardo, D.G.; Brennan, D.J.; Rexhepaj, E.; Ruffell, B.; Shiao, S.L.; Madden, S.F.; Gallagher, W.M.; Wadhwani, N.; Keil, S.D.; Junaid, S.A.; et al. Leukocyte complexity predicts breast cancer survival and functionally regulates response to chemotherapy. Cancer Discov. 2011, 1, 54-67. [CrossRef]

7. Sugimura, K.; Miyata, H.; Tanaka, K.; Takahashi, T.; Kurokawa, Y.; Yamasaki, M.; Nakajima, K.; Takiguchi, S.; Mori, M.; Doki, Y. High infiltration of tumor-associated macrophages is associated with a poor response to chemotherapy and poor prognosis of patients undergoing neoadjuvant chemotherapy for esophageal cancer. J. Surg. Oncol. 2015, 111, 752-759. [CrossRef]

8. Garcia-Martinez, E.; Gil, G.L.; Benito, A.C.; Gonzalez-Billalabeitia, E.; Conesa, M.A.; Garcia Garcia, T.; Garcia-Garre, E.; Vicente, V.; Ayala de la Pena, F. Tumor-infiltrating immune cell profiles and their change after neoadjuvant chemotherapy predict response and prognosis of breast cancer. Breast Cancer Res. 2014, 16, 488. [CrossRef]

9. Hamy, A.S.; Pierga, J.Y.; Sabaila, A.; Laas, E.; Bonsang-Kitzis, H.; Laurent, C.; Vincent-Salomon, A.; Cottu, P.; Lerebours, F.; Rouzier, R.; et al. Stromal lymphocyte infiltration after neoadjuvant chemotherapy is associated with aggressive residual disease and lower disease-free survival in HER2-positive breast cancer. Ann. Oncol. 2017, 28, 2233-2240. [CrossRef]

10. Predina, J.D.; Judy, B.; Aliperti, L.A.; Fridlender, Z.G.; Blouin, A.; Kapoor, V.; Laguna, B.; Nakagawa, H.; Rustgi, A.K.; Aguilar, L.; et al. Neoadjuvant in situ gene-mediated cytotoxic immunotherapy improves postoperative outcomes in novel syngeneic esophageal carcinoma models. Cancer Gene Ther. 2011, 18, 871-883. [CrossRef]

11. Tsuchikawa, T.; Md, M.M.; Yamamura, Y.; Shichinohe, T.; Hirano, S.; Kondo, S. The immunological impact of neoadjuvant chemotherapy on the tumor microenvironment of esophageal squamous cell carcinoma. Ann. Surg. Oncol. 2012, 19, 1713-1719. [CrossRef] [PubMed]

12. Nakasone, E.S.; Askautrud, H.A.; Kees, T.; Park, J.H.; Plaks, V.; Ewald, A.J.; Fein, M.; Rasch, M.G.; Tan, Y.X.; Qiu, J.; et al. Imaging tumor-stroma interactions during chemotherapy reveals contributions of the microenvironment to resistance. Cancer Cell 2012, 21, 488-503. [CrossRef] [PubMed]

13. Berg, E.L.; Robinson, M.K.; Mansson, O.; Butcher, E.C.; Magnani, J.L. A carbohydrate domain common to both sialyl Le(a) and sialyl $\mathrm{Le}(\mathrm{X})$ is recognized by the endothelial cell leukocyte adhesion molecule ELAM-1. J. Biol. Chem. 1991, 266, 14869-14872. [PubMed]

14. Welply, J.K.; Keene, J.L.; Schmuke, J.J.; Howard, S.C. Selectins as potential targets of therapeutic intervention in inflammatory diseases. Biochim. Biophys. Acta 1994, 1197, 215-226. [CrossRef]

15. Zetter, B.R. Adhesion molecules in tumor metastasis. Semin. Cancer Biol. 1993, 4, 219-229.

16. Sackstein, R. Glycosyltransferase-programmed stereosubstitution (GPS) to create HCELL: Engineering a roadmap for cell migration. Immunol. Rev. 2009, 230, 51-74. [CrossRef]

17. Charpin, C.; Bergeret, D.; Garcia, S.; Andrac, L.; Martini, F.; Horschowski, N.; Choux, R.; Lavaut, M.N. ELAM selectin expression in breast carcinomas detected by automated and quantitative immunohistochemical assays. Int. J. Oncol. 1998, 12, 1041-1048. [CrossRef]

18. Muller, A.M.; Weichert, A.; Muller, K.M. E-cadherin, E-selectin and vascular cell adhesion molecule: Immunohistochemical markers for differentiation between mesothelioma and metastatic pulmonary adenocarcinoma? Virchows Arch. 2002, 441, 41-46. [CrossRef]

19. Nguyen, M.; Corless, C.L.; Kraling, B.M.; Tran, C.; Atha, T.; Bischoff, J.; Barsky, S.H. Vascular expression of E-selectin is increased in estrogen-receptor-negative breast cancer: A role for tumor-cell-secreted interleukin-1 alpha. Am. J. Pathol. 1997, 150, 1307-1314.

20. Matsuura, N.; Narita, T.; Hiraiwa, N.; Hiraiwa, M.; Murai, H.; Iwase, T.; Funahashi, H.; Imai, T.; Takagi, H.; Kannagi, R. Gene expression of fucosyl- and sialyl-transferases which synthesize sialyl Lewisx, the carbohydrate ligands for E-selectin, in human breast cancer. Int. J. Oncol. 1998, 12, 1157-1164. [CrossRef]

21. Kang, S.A.; Hasan, N.; Mann, A.P.; Zheng, W.; Zhao, L.; Morris, L.; Zhu, W.; Zhao, Y.D.; Suh, K.S.; Dooley, W.C.; et al. Blocking the adhesion cascade at the premetastatic niche for prevention of breast cancer metastasis. Mol. Ther. 2015, 23, 1044-1054. [CrossRef] [PubMed]

22. Shaked, Y. The pro-tumorigenic host response to cancer therapies. Nat. Rev. Cancer 2019. [CrossRef] [PubMed]

23. Abdel-Daim, M.M.; Kilany, O.E.; Khalifa, H.A.; Ahmed, A.A.M. Allicin ameliorates doxorubicin-induced cardiotoxicity in rats via suppression of oxidative stress, inflammation and apoptosis. Cancer Chemother. Pharmacol. 2017, 80, 745-753. [CrossRef] [PubMed] 
24. Abushouk, A.I.; Ismail, A.; Salem, A.M.A.; Afifi, A.M.; Abdel-Daim, M.M. Cardioprotective mechanisms of phytochemicals against doxorubicin-induced cardiotoxicity. Biomed. Pharmacother. 2017, 90, 935-946. [CrossRef]

25. Abushouk, A.I.; Salem, A.M.A.; Saad, A.; Afifi, A.M.; Afify, A.Y.; Afify, H.; Salem, H.S.E.; Ghanem, E.; Abdel-Daim, M.M. Mesenchymal Stem Cell Therapy for Doxorubicin-Induced Cardiomyopathy: Potential Mechanisms, Governing Factors, and Implications of the Heart Stem Cell Debate. Front. Pharmacol. 2019, 10, 635. [CrossRef]

26. Quagliariello, V.; Vecchione, R.; Coppola, C.; Di Cicco, C.; De Capua, A.; Piscopo, G.; Paciello, R.; Narciso, V.; Formisano, C.; Taglialatela-Scafati, O.; et al. Cardioprotective Effects of Nanoemulsions Loaded with Anti-Inflammatory Nutraceuticals against Doxorubicin-Induced Cardiotoxicity. Nutrients 2018, 10, 1304. [CrossRef]

27. Ridker, P.M.; Everett, B.M.; Thuren, T.; MacFadyen, J.G.; Chang, W.H.; Ballantyne, C.; Fonseca, F.; Nicolau, J.; Koenig, W.; Anker, S.D.; et al. Antiinflammatory Therapy with Canakinumab for Atherosclerotic Disease. N. Engl. J. Med. 2017, 377, 1119-1131. [CrossRef]

28. Zhu, J.; Zhang, J.; Zhang, L.; Du, R.; Xiang, D.; Wu, M.; Zhang, R.; Han, W. Interleukin-1 signaling mediates acute doxorubicin-induced cardiotoxicity. Biomed. Pharmacother. 2011, 65, 481-485. [CrossRef]

29. Sauter, K.A.; Wood, L.J.; Wong, J.; Iordanov, M.; Magun, B.E. Doxorubicin and daunorubicin induce processing and release of interleukin-1 $\beta$ through activation of the NLRP3 inflammasome. Cancer Biol. Ther. 2011, 11, 1008-1016. [CrossRef]

30. Engelhardt, B.; Kappos, L. Natalizumab: Targeting alpha4-integrins in multiple sclerosis. Neurodegener. Dis. 2008, 5, 16-22. [CrossRef]

31. Ahn, G.O.; Tseng, D.; Liao, C.H.; Dorie, M.J.; Czechowicz, A.; Brown, J.M. Inhibition of Mac-1 (CD11b/CD18) enhances tumor response to radiation by reducing myeloid cell recruitment. Proc. Natl. Acad. Sci. USA 2010, 107, 8363-8368. [CrossRef] [PubMed]

32. Ries, C.H.; Cannarile, M.A.; Hoves, S.; Benz, J.; Wartha, K.; Runza, V.; Rey-Giraud, F.; Pradel, L.P.; Feuerhake, F.; Klaman, I.; et al. Targeting tumor-associated macrophages with anti-CSF-1R antibody reveals a strategy for cancer therapy. Cancer Cell 2014, 25, 846-859. [CrossRef] [PubMed]

33. Pahler, J.C.; Tazzyman, S.; Erez, N.; Chen, Y.Y.; Murdoch, C.; Nozawa, H.; Lewis, C.E.; Hanahan, D. Plasticity in tumor-promoting inflammation: Impairment of macrophage recruitment evokes a compensatory neutrophil response. Neoplasia 2008, 10, 329-340. [CrossRef] [PubMed]

34. Bevilacqua, M.P.; Pober, J.S.; Mendrick, D.L.; Cotran, R.S.; Gimbrone, M.A., Jr. Identification of an inducible endothelial-leukocyte adhesion molecule. Proc. Natl. Acad. Sci. USA 1987, 84, 9238-9242. [CrossRef]

35. Martens, C.L.; Cwirla, S.E.; Lee, R.Y.; Whitehorn, E.; Chen, E.Y.; Bakker, A.; Martin, E.L.; Wagstrom, C.; Gopalan, P.; Smith, C.W.; et al. Peptides which bind to E-selectin and block neutrophil adhesion. J. Biol. Chem. 1995, 270, 21129-21136. [CrossRef]

36. Ernst, B.; Magnani, J.L. From carbohydrate leads to glycomimetic drugs. Nat. Rev. Drug Discov. 2009, 8, 661-677. [CrossRef]

37. Chapman, P.T.; Jamar, F.; Keelan, E.T.; Peters, A.M.; Haskard, D.O. Use of a radiolabeled monoclonal antibody against E-selectin for imaging of endothelial activation in rheumatoid arthritis. Arthritis Rheumatol. 1996, 39, 1371-1375. [CrossRef]

38. Natoni, A.; Smith, T.A.G.; Keane, N.; McEllistrim, C.; Connolly, C.; Jha, A.; Andrulis, M.; Ellert, E.; Raab, M.S.; Glavey, S.V.; et al. E-selectin ligands recognised by HECA452 induce drug resistance in myeloma, which is overcome by the E-selectin antagonist, GMI-1271. Leukemia 2017, 31, 2642-2651. [CrossRef]

39. Foy, J.W.; Rittenhouse, K.; Modi, M.; Patel, M. Local tolerance and systemic safety of pegaptanib sodium in the dog and rabbit. J. Ocul. Pharmacol. Ther. 2007, 23, 452-466. [CrossRef]

40. Cerchia, L.; Esposito, C.L.; Camorani, S.; Catuogno, S.; Franciscis, V. Coupling Aptamers to Short Interfering RNAs as Therapeutics. Pharmaceuticals (Basel) 2011, 4, 1434-1449. [CrossRef]

41. Sun, H.; Zhu, X.; Lu, P.Y.; Rosato, R.R.; Tan, W.; Zu, Y. Oligonucleotide aptamers: New tools for targeted cancer therapy. Mol. Ther. Nucleic Acids 2014, 3, e182. [CrossRef] [PubMed]

42. Bruno, J.G. Long Shelf Life of a Lyophilized DNA Aptamer Beacon Assay. J. Fluoresc. 2017, $27,439-441$. [CrossRef] [PubMed]

43. Lakhin, A.V.; Tarantul, V.Z.; Gening, L.V. Aptamers: Problems, solutions and prospects. Acta Nat. 2013, 5, 34-43. [CrossRef] 
44. Morita, Y.; Leslie, M.; Kameyama, H.; Volk, D.E.; Tanaka, T. Aptamer Therapeutics in Cancer: Current and Future. Cancers (Basel) 2018, 10, 80. [CrossRef] [PubMed]

45. Ni, S.; Yao, H.; Wang, L.; Lu, J.; Jiang, F.; Lu, A.; Zhang, G. Chemical Modifications of Nucleic Acid Aptamers for Therapeutic Purposes. Int. J. Mol. Sci. 2017, 18, 1683. [CrossRef]

46. Griffin, L.C.; Tidmarsh, G.F.; Bock, L.C.; Toole, J.J.; Leung, L.L. In vivo anticoagulant properties of a novel nucleotide-based thrombin inhibitor and demonstration of regional anticoagulation in extracorporeal circuits. Blood 1993, 81, 3271-3276. [CrossRef]

47. Kang, S.A.; Tsolmon, B.; Mann, A.P.; Zheng, W.; Zhao, L.; Zhao, Y.D.; Volk, D.E.; Lokesh, G.L.; Morris, L.; Gupta, V.; et al. Safety evaluation of intravenously administered mono-thioated aptamer against E-selectin in mice. Toxicol. Appl. Pharmacol. 2015, 287, 86-92. [CrossRef]

48. Kryza, D.; Debordeaux, F.; Azéma, L.; Hassan, A.; Paurelle, O.; Schulz, J.; Savona-Baron, C.; Charignon, E.; Bonazza, P.; Taleb, J.; et al. Ex Vivo and In Vivo Imaging and Biodistribution of Aptamers Targeting the Human Matrix MetalloProtease-9 in Melanomas. PLoS ONE 2016, 11, e0149387. [CrossRef]

49. Kang, S.A.; Blache, C.A.; Bajana, S.; Hasan, N.; Kamal, M.; Morita, Y.; Gupta, V.; Tsolmon, B.; Suh, K.S.; Gorenstein, D.G.; et al. The effect of soluble E-selectin on tumor progression and metastasis. BMC Cancer 2016, 16, 331. [CrossRef]

50. Mann, A.P.; Somasunderam, A.; Nieves-Alicea, R.; Li, X.; Hu, A.; Sood, A.K.; Ferrari, M.; Gorenstein, D.G.; Tanaka, T. Identification of thioaptamer ligand against E-selectin: Potential application for inflamed vasculature targeting. PLOS ONE 2010, 5. [CrossRef]

51. Morita, Y.; Zhang, R.; Leslie, M.; Adhikari, S.; Hasan, N.; Chervoneva, I.; Rui, H.; Tanaka, T. Pathologic evaluation of tumor-associated macrophage density and vessel inflammation in invasive breast carcinomas. Oncol. Lett. 2017, 14, 2111-2118. [CrossRef] [PubMed]

52. Movahedi, K.; Laoui, D.; Gysemans, C.; Baeten, M.; Stange, G.; Van den Bossche, J.; Mack, M.; Pipeleers, D.; In't Veld, P.; De Baetselier, P.; et al. Different tumor microenvironments contain functionally distinct subsets of macrophages derived from Ly6C(high) monocytes. Cancer Res. 2010, 70, 5728-5739. [CrossRef] [PubMed]

(C) 2020 by the authors. Licensee MDPI, Basel, Switzerland. This article is an open access article distributed under the terms and conditions of the Creative Commons Attribution (CC BY) license (http://creativecommons.org/licenses/by/4.0/). 